\title{
Knowledge and Practices of Exclusive Breastfeeding among Women in Rural Uttar Pradesh
}

\section{Akanksha Verma ${ }^{1 *}$ and Priyanka Dixit ${ }^{2}$}

${ }^{1}$ India Health Action Trust, Uttar Pradesh Technical Support Unit, Lucknow, India

${ }^{2}$ School of Health Systems Studies, Tata Institute of Social Sciences, Govandi Station Road, Deonar, Mumbai, India

\begin{abstract}
Background: Breast feeding has been defines as the practice through which adequate nutrition and other nutritional requirements of the new born are being taken care of. Exclusively Breast feeding is a term used to define the process by which only breast milk is given to the new born till the first six months of life. But it has been enveloped in many layers of the factors like the Social and cultural attitudes which further affect the practice and rate of breast feeding worldwide and also in India which is considered to be one of the major reasons for the IMR and under- 5 mortality rate.
\end{abstract}

Methods: Cross-sectional study was conducted using a semi-structured interview schedule. A total of 256 mothers who were in their reproductive age and had delivered in the last 12 months were interviewed.

Results: While studying the practice of exclusive breast-feeding among the participants it was seen that the practice of exclusive breast-feeding were low among them, i.e., only $24.8 \%$ of the total women going for the practice of exclusive breast-feeding. On looking at the various reasons for the early cessation of exclusive breast feeding, multiple responses were seen like breast related factors included reasons like breast feeding were painful or the baby had difficulty in swallowing. Cultural belief was seen to be one of most dominant factor for the practice of giving pre-lacteal feed. It was seen that many factors associated with the practice of breastfeeding including psychosocial factors, maternal sociodemographic characteristics, hospital practices and environmental support, etc.

Conclusion: Nutrition has been considered to be one of the basis of a healthy foundation of the future. Breast milk and breast feeding has been considered to be the best nutrition for the new born till the first six months of age. Under nutrition during first two years impairs not only the cognitive development, intelligence, strength, energy and productivity. Although breast feeding is almost universal in India the rate of early initiation of breast feeding and exclusive breast feeding are dismally low. Several $f$ actors can be attributed to this which has a great influence on the breast feeding practices.

Keywords: Exclusive breast feeding; Pre-lacteal fees; Early initiation of breast feeding; Breastfeeding promotion network of India; Aaganwadi workers; Ante-natal check-up

\section{Introduction}

Nutrition is one of the very basic necessities for each species to live, survive, sustain as well as essential to grow, develop and to lead a productive life. The word 'nutrition' has been derived from the word 'nutricus' which means to 'suckle at breast'. During pregnancy the placenta is the main source of nutrition to the growing foetus. After delivery one of the first gifts or boon received by a baby is from the mother which is a promise by her to her baby to provide everything needed for this little Considering a life course perspective it can be seen that nutrition to the baby is a very important and effective link which will cater to many issues like mal-nutrition, mortality, morbidities which may have debilitating effects on not only on the individual but also on the society as a whole.

According to the World Health Organisation (2009) "Exclusive breastfeeding means that an infant receives only breast milk from his or her mother or a wet nurse, or expressed breast milk, and no other liquids or solids, not even water, with the exception of oral rehydration solution, drops or syrups consisting of vitamins, minerals supplements or medicines"

Breastfeeding confers both the short and the long-term benefits to both the child and mother. One of the basic functions which early initiation of breastfeeding does is to ensure an early skin-to-skin contact between the mother and the new born which is very important in reducing the chances of hypothermia in the baby and also helps in establishing the bond between the mother and her child. The other benefits of breast feeding include protecting children against a variety of acute and chronic disorders which contributes to the reduction of neo-natal mortality.

It has also been seen that the cases of diarrhoea and pneumonia which are two of the most important causes of neo-natal and infant mortality are more common and more severe in those children who are artificially fed (WHO/UNICEF (2003) Global strategy for infant and young child feeding. Geneva, World Health Organization). It has been seen that breast feeding had an important role in the proper and better cognitive development of the baby [1-5].

In 1929, Hoefer and Hardy had observed that there was a positive association between breastfeeding and the intelligence among children aged between 7 to 13 years. Further in 1950, Douglas reported that the duration of breastfeeding had an inverse relationship with the age at which the child started walking. For the mother, it has been further seen

*Corresponding author: Akanksha Verma, District Nutrition Specialist, India Health Action Trust, Uttar Pradesh Technical Support Unit, Lucknow, India, Tel: 0522 4931777; E-mail: drakankshaverma@rediffmail.com

Received July 17, 2016; Accepted July 30, 2016; Published August 05, 2016

Citation: Verma A, Dixit P (2016) Knowledge and Practices of Exclusive Breastfeeding among Women in Rural Uttar Pradesh. J Neonatal Biol 5: 228. doi: 10.4172/2167-0897.1000228

Copyright: @ 2016 Verma A, et al. This is an open-access article distributed under the terms of the Creative Commons Attribution License, which permits unrestricted use, distribution, and reproduction in any medium, provided the original author and source are credited. 
that early initiation of breastfeeding reduces the mother's risk of postpartum haemorrhage, which is one of the leading causes of maternal mortality. Mothers who had exclusively breastfeed had less than a $2 \%$ risk of becoming pregnant again in the first 6 months postpartum [510].

But breast feeding has been enveloped in many layers of the factors which shape the patterns of breast feeding among the women. Of the many factors some of the factors which have been seen to have a significant role are the social and cultural attitudes which shape the structural context for breastfeeding. Taking the health systems, healthcare providers influence on the breast feeding practices it is seen that the support about the feeding decisions before and after birth and the dissemination of the knowledge and information have been seen to have a greater impact on exclusive and continued breastfeeding. Other factors include high-risk pregnancies, assisted delivery and long hospital stays, maternal illness, and preterm, ill, which can further result in breastfeeding starting later. Family support and the practices and experience of female relatives have also been seen to affect the incidence and duration of breastfeeding [11-17].

In many of the traditional societies, colostrum had been viewed to be harmful and was discarded, and further the use of pre-lacteal feeds can delay breastfeeding. The attitudes and preferences of the fathers were also to affect breastfeeding: those women whose partners were supportive of breastfeeding breastfeed for longer. Also women's work is one of the leading motives for not breastfeeding or for early weaning. Its effect is multidimensional, which may include fatigue, practicality etc.

Previous studies have shown the strong association between exclusively breastfed and child survival (Horta, 2013; Public Health Importance of Optimal Infant and Young Child Feeding Practices (IYCF), 2015). However, estimate indicated that in India, only $46.3 \%$ infants were exclusively breastfed for the first 6 months (National Family Health Survey-3). Uttar Pradesh having a load of population about 200 million, $1 / 6$ of the country's population breastfeeding practices is not up to the mark. Annual health survey 2012-13 reflects that only $39.4 \%$ of new born receive breast milk within one hour and about $20.8 \%$ children sustain breastfeeding till 35 weeks. (Annual Health Survey, 2012-2013). Infant mortality rate in Uttar Pradesh contributes to 68 per 1000 live births. Prevalence of diarrhoeal diseases in infants contributes to $10.8 \%$ of infants and $27.4 \%$ Upper Respiratory Tract Infection. Uttar Pradesh is the largest contributor to child mortality in India and breastfeeding practices are among the lowest in the country with only $8.2 \%$ babies being breastfed exclusively for 6 months and $15.4 \%$ mothers initiating breastfeeding in 1 hour (DLHS3) $[18-24]$.

In District Amroha of Uttar Pradesh having a population of 1.85 million, breast feeding practices within one hour of birth is only $33.2 \%$ while sustaining it till 35 weeks. Is only $10.4 \%$ infant mortality rate is 72 per 1000 live births. In young infants prevalence of diarrhoeal diseases is $8.3 \%$ and Acute RTI is 33 .

Thus the current study aimed at understanding the perceptions of the mothers in rural areas of Amroha district of Uttar Pradesh about the importance of breast feeding and the actual practices followed by them and further to study the various factors which play a role in it [25-30].

\section{Methodology}

This study was conducted in the rural areas of the four blocks of Amroha district, previously known as Jyotiba Phule (J.P) Nagar, i.e.,
Blocks Gajraula, Rehra and Hasanpur in Amroha district of Uttar Pradesh. The cross sectional study design was used for this research.

Amroha district has 6 blocks. Of these 6 blocks 4 were randomly selected based accessibility criteria. As each of the selected blocks has about 60 to 80 villages, 6 villages from each block were randomly selected. From each village the list of mothers who had delivered in the past 12 months were taken from the ASHA workers. From the above list women whose last born child was not less than 6 months were selected.

From each selected village, a probability proportional to size sampling was used considering the proportion of population of each block. From the final list of all the eligible mothers from all the villages in all the four blocks, the respondents were selected using a simple random sampling where every 10th woman was selected. If any respondent was not willing to participate in the study, the next eligible woman was chosen and a total sample of 256 was taken for the study.

The universe consists of all the married women in the reproductive age group, i.e., between 15 to 45 years of age who have delivered in the past 12 months and the age of their last born child was not less than 6 months at the time of interview.

For the process of data collection, semi-structured interview schedule made in English which was converted into Hindi was used in order to collect the data from the respondents. The first section of the interview schedule consisted the questions on the socio-demographic profile, educational status of the respondents which included question about the age of the respondent, religion, caste, migration status of the respondent, Ownership of household, Type of family, Years of education of the respondent, Years of education of the respondent's husband, etc. were asked [31-35].

The second section of the interview schedule included the questions about the delivery and the number of children of the respondents like where and when was the last child delivered, how was the child delivered, has the respondent received any information about the breast feeding practices during her pregnancy and the source of that information, etc. Further question were asked to assess the perception of respondent about the importance of the colostrum and exclusive breast feeding for the new born and also about the actual practices followed by them were asked. Finally the questions regarding the social and cultural beliefs regarding colostrum and exclusive breast feeding were asked.

Data analysis was conducted using SPSS 22. Descriptive analysis was done to describe the characteristics of study population. Further other statistical tools like Chi square have been used to measure of association and logistic regression was used to check the significant factors affecting the outcome variable.

\section{Conceptual frame work}

Breastfeeding is an unequalled process of providing the nutrition to the new born which can help in growth and development of the new born. It is a complex procedure involving both the psychological and physiological processes which in turn is governed by a lot of social, economic and other cultural factors (Figure 1). These factors affect breastfeeding and exclusive breastfeeding in different directions and to varying degrees depending on culture [36-40].

\section{Results}

The above Tables 1 and 2 shows the knowledge among the respondents about the various aspects of breast feeding practices. 
Citation: Verma A, Dixit P (2016) Knowledge and Practices of Exclusive Breastfeeding among Women in Rural Uttar Pradesh. J Neonatal Biol 5: 228. doi: $10.4172 / 2167-0897.1000228$

Page 3 of 7

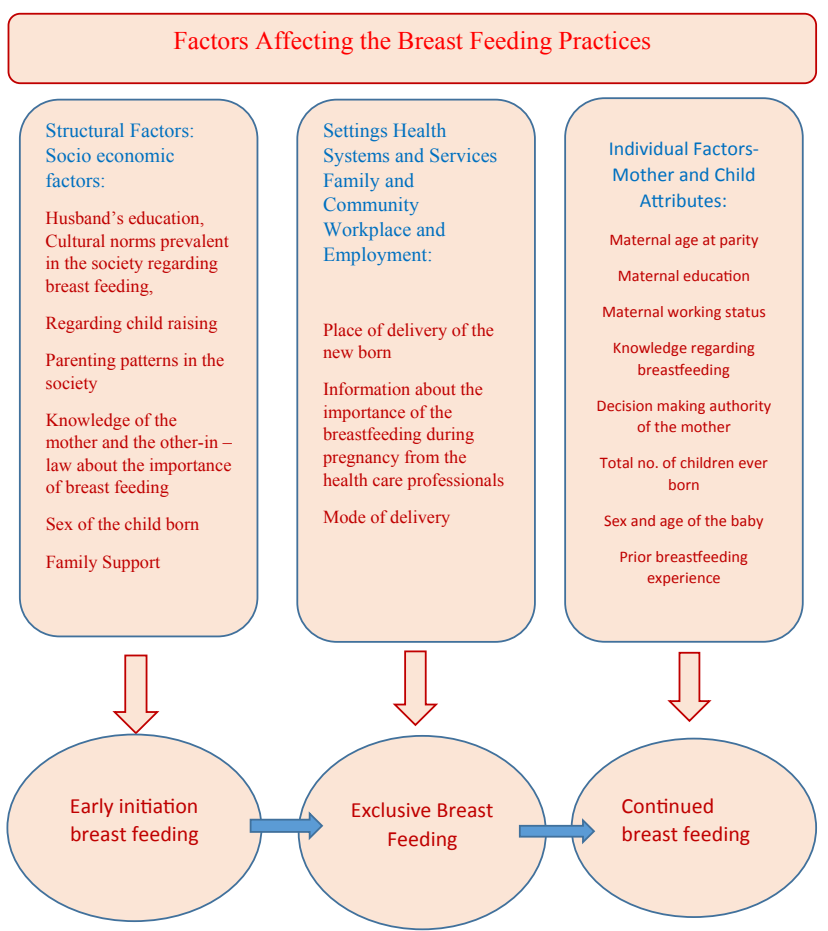

Figure 1: Factors affecting the breast feeding practices.

\begin{tabular}{|l|c|c|}
\hline Age of the respondents (years) & Total & $\%$ \\
\hline$<21$ & 22 & 8.3 \\
\hline $22-25$ & 130 & 50.8 \\
\hline $26-30$ & 93 & 35.1 \\
\hline$>31$ & 11 & 4.2 \\
\hline Literacy wise distribution of study subjects $(\mathrm{N}=256)$ & $\mathrm{N}$ & $\%$ \\
\hline Illiterate & 34 & 12.8 \\
\hline Primary & 39 & 15.2 \\
\hline Middle school & 79 & 32 \\
\hline High school & 58 & 21.8 \\
\hline Higher secondary & 27 & 10.5 \\
\hline Graduation and above & 19 & 7.4 \\
\hline Working status of the respondent: $(\mathrm{N}=256)$ & $\mathrm{N}$ & $\%$ \\
\hline Working & 149 & 58 \\
\hline Non-working & 107 & 42 \\
\hline Family type of the respondent: & $\mathrm{N}$ & $\%$ \\
\hline Nuclear & 160 & 62 \\
\hline Joint & 96 & 38 \\
\hline Total & 256 & 100 \\
\hline
\end{tabular}

Table 1: Demographic characteristics of the participants.

It can be seen that 61.7 percent of them said that they were aware that colostrum was important for the growth and development of their baby while 38.3 percent said that they were not aware of it. 80 percent of them said that breast milk was important while the rest said that it was not important. 50.4 percent said that they felt that it was adequately nutritious while the rest 49.6 percent said that they did not consider being adequately nutritious for the infant. 37.5 percent mothers reported that they were aware that Exclusive Breast Feeding is important for the infant, while the rest, i.e., 62.5 percent said that they were not aware about it. 52.8 percent said that they were aware that Exclusive Breast Feeding is important for the infant, while the rest, i.e.,
41.1 percent said that they were not aware about it. 76.1 percent of the respondents said that they considered that pre-lacteal feeds were very important considering its cultural component as well as the nutrient content for the baby whereas 23.9 percent said that pre-lacteal feeds were not important for the baby [41-46].

From the above table, it can be seen that majority of the women, i.e., 84.4 percent of the total had undergone at least one ANC during their pregnancy while rest did not under go any ANC check-up. While studying the place of the ante-natal check-up, it was established that 73.2 percent of them went to a government facility whereas the rest 26.8 percent went to a private health care facility for their ANC checkup.

Taking into consideration about any prior information received about the importance of breast feeding, it was seen that only 42.5 percent of the respondents had some prior knowledge regarding the importance of breast feeding while majority of them, i.e., 57.5 percent had no knowledge or information about the importance of breast feeding for the growth and development of the baby. It was seen that for the majority of the participants, i.e., 65.2 percent, the place of

\begin{tabular}{|c|c|c|}
\hline Prior knowledge about the importance of colostrum & $\mathbf{N}$ & $(\%)$ \\
\hline Yes & 158 & 61.7 \\
\hline No & 98 & 38.3 \\
\hline Do you think breast milk is important for the baby & $\mathbf{N}$ & $(\%)$ \\
\hline Yes & 205 & 80 \\
\hline No & 51 & 20 \\
\hline $\begin{array}{l}\text { Do you think breast milk contains all the nutrients } \\
\text { required for the baby for the first six month }\end{array}$ & $\mathbf{N}$ & $(\%)$ \\
\hline Yes & 129 & 50.4 \\
\hline No & 127 & 49.6 \\
\hline $\begin{array}{l}\text { Knowledge about the importance of early initiation of } \\
\text { breast feeding }\end{array}$ & $\mathrm{N}$ & $(\%)$ \\
\hline Yes & 96 & 37.5 \\
\hline No & 160 & 62.5 \\
\hline $\begin{array}{l}\text { Knowledge about the importance of exclusive breast } \\
\text { feeding for the infant }\end{array}$ & $\mathbf{N}$ & $(\%)$ \\
\hline Yes & 135 & 52.8 \\
\hline No & 121 & 41.1 \\
\hline Do you think pre-lacteal feed is important for the baby & $\mathbf{N}$ & $(\%)$ \\
\hline Yes & 195 & 76.1 \\
\hline No & 61 & 23.9 \\
\hline ANC Check-ups at least one & $\mathrm{N}=\mathbf{2 5 6}$ & $(\%)$ \\
\hline Yes & 215 & 84.4 \\
\hline No & 41 & 15.6 \\
\hline Frequency of ANC & $\mathrm{N}=\mathbf{2 1 5}$ & $(\%)$ \\
\hline 1-3 ANC & 125 & 58.3 \\
\hline$\geq 3$ ANC & 90 & 41.7 \\
\hline Place of ANC Check-ups & $\mathrm{N}=\mathbf{2 1 5}$ & $(\%)$ \\
\hline Govt. & 157 & 73.2 \\
\hline Private & 58 & 26.8 \\
\hline Any BF information provided & $N=256$ & $(\%)$ \\
\hline Yes & 109 & 42.5 \\
\hline No & 147 & 57.5 \\
\hline Mode of Delivery & $\mathbf{N}$ & (\%) \\
\hline Normal Vaginal & 215 & 84 \\
\hline Assisted Vaginal & 8 & 3.2 \\
\hline Caesarean & 3 & 12.8 \\
\hline Total & 256 & 100 \\
\hline
\end{tabular}

Table 2: Knowledge about different component of breastfeeding among the respondents. 
delivery was a government health care facility whereas the other 26.4 percent went to a private health care setting for their delivery and the rest 8.4 percent delivered the child at home.

On retrospection, the mode of delivery for the majority of the respondents was a normal vaginal delivery while for 12.8 percent of the respondents reported caesarean section and for a small percentage, i.e., 3.2 percent, it was an assisted vaginal delivery.

The above Table 3 gives a glimpse of the actual practices being followed by the participants. It can be seen that majority of the participants, i.e., 70.8 percent did not initiate breast feeding their babies within an hour after delivery and only 29.2 percent of them initiated it within an hour. When the reasons were asked from the respondents

\begin{tabular}{|c|c|c|}
\hline \multicolumn{2}{|c|}{ Initiation of Breastfeeding among participants ( $N=256)$} & \multirow{2}{*}{$\begin{array}{c}\text { Percentage } \\
29.2\end{array}$} \\
\hline Early Initiation (within first hour) & 74 & \\
\hline Late Initiation & 182 & 70.8 \\
\hline \multicolumn{3}{|l|}{ Reasons for late initiation of breast feeding } \\
\hline Reason $^{*}$ & \multicolumn{2}{|c|}{ Total $(\mathrm{N}=177)$} \\
\hline Milk did not come in yet & 89 & 50.2 \\
\hline Baby not accepting breast & 61 & 34.5 \\
\hline Cultural beliefs & 65 & 36.7 \\
\hline Baby ill & 32 & 18.1 \\
\hline Mother ill & 8 & 4.5 \\
\hline Don't know & 13 & 7.3 \\
\hline \multicolumn{3}{|l|}{ Pre-lacteal feeds given $\mathrm{N}=\mathbf{2 5 6}$} \\
\hline Yes & 172 & 67.2 \\
\hline No & 84 & 32.8 \\
\hline \multicolumn{3}{|l|}{ Type of pre-lacteal feed given $\mathrm{N}=172$} \\
\hline Water & 63 & 36.6 \\
\hline Honey & 51 & 29.6 \\
\hline Cow's milk & 21 & 12.2 \\
\hline Sugar/salt solution & 18 & 10.4 \\
\hline Infant formula & 11 & 6.3 \\
\hline Turmeric syrup & 8 & 4.6 \\
\hline \multicolumn{3}{|l|}{ Colostrum given by participants $(\mathrm{N}=\mathbf{2 5 6})$} \\
\hline (Yes) & 168 & 65.6 \\
\hline Dump yellow milk (No) & 88 & 34.4 \\
\hline \multicolumn{3}{|c|}{ Exclusive Breastfeeding among participants $(\mathrm{N}=256)$} \\
\hline Exclusive & 64 & 24.8 \\
\hline Non-Exclusive & 192 & 75.2 \\
\hline \multicolumn{3}{|c|}{$\begin{array}{l}\text { Reasons given by mothers for early cessation of breastfeeding (before six } \\
\text { months) }\end{array}$} \\
\hline Reasons* $\mathrm{N}=192(\%)$ & \multicolumn{2}{|c|}{ Reasons $(\mathrm{N}=192)$} \\
\hline Breast related problems $\mathrm{N}=30$ (15.4) & $\mathbf{N}$ & $\%$ \\
\hline Baby had trouble sucking & 11 & 37.9 \\
\hline Painful breast and fever & 6 & 20.7 \\
\hline Breastfeeding was too painful & 4 & 13.8 \\
\hline Locational Failure & 8 & 27.6 \\
\hline Nutritional factor $\mathrm{N}=123$ & \multicolumn{2}{|c|}{$\mathrm{N}=123(63.8)$} \\
\hline Breast milk alone did not satisfy my baby & 48 & 39.1 \\
\hline Baby was not gaining enough weight & 40 & 32.5 \\
\hline Didn't have enough milk & 35 & 28.3 \\
\hline Psychosocial factor $\mathbf{N}=\mathbf{3 8}$ & \multicolumn{2}{|c|}{$\mathrm{N}=38$ (19.7) } \\
\hline Returning to work 33 (86.5) & 33 & 86.5 \\
\hline Too many household duties & 3 & 8.1 \\
\hline Mother worried/ stressed & 2 & 5.4 \\
\hline Medical factor $\mathrm{N}=39$ & \multicolumn{2}{|c|}{$\mathrm{N}=39(20.2)$} \\
\hline My baby became sick and could not breastfeed & 28 & 71.1 \\
\hline I was sick or had to take medicine & 11 & 28.9 \\
\hline
\end{tabular}

Table 3: Practices of breastfeeding followed among the respondents. for not early initiation of breast feeding, multiple responses were obtained from the respondents which included reasons like milk did not come out immediately ( 89 percent) while other reasons included baby not accepting the breast milk which was said by 34.5 percent of the respondents. Further other reasons cited for non-initiating breast feeding within one hour were cultural beliefs 36.7 percent the baby was ill or the mother was ill. 7.3 percent of the respondents said that did not know the reason for this delay. It was seen that 172 out of the total 257 agreed to have given some kind of pre-lacteal feed to the baby while 84 of them did not give any pre-lacteal feed to the baby. For the type of pre-lacteal feeds given to the infant it was seen that in majority of the cases water was the pre-lacteal feed given (36.6\%), followed by honey 34.3 percent, cow's milk 12.2 percent, sugar/salt solution 10.4 percent and infant formula was given in 6.3 percent of the cases.

Cultural belief was seen to be one of most dominant factor for the practice of giving pre-lacteal feed to the infant which was seen in 78 percent of the total cases. Other reasons cited for giving pre-lacteal feeds were baby's non acceptance to breast milk, non-production of milk, ill health of the baby. Further, 65.6 percent of the total respondents said that they gave the first yellow milk or the colostrum to their baby while 34.4 percent of them discarded the colostrum. The practice of exclusive breast-feeding was were low among them, i.e., 24.8 percent of the total going for the practice of exclusive breast-feeding while the rest were not following it.

On looking at the various reasons for the early cessation of exclusive breast feeding, multiple responses were seen. Reasons like breast related factors included reasons like breast feeding were painful or the baby had difficulty in swallowing. Further other factors which were given by the respondents were nutritional factors 63.8 percent which included the perception and the feeling of the mother that breast milk was not adequate for the baby; also that baby was not gaining weight only because of breast milk and required supplementation.

The above Table 4 shows that there are various factors which were associated with the practices of breast feeding and were statistically significant. There was strong association between early initiation of breast feeding and exclusive breast feeding and the factors like Age of the mother. The early initiation of breastfeeding was higher amongst younger mothers of age 25 years or less ( 48 percent) as compared to mothers who were above 25 years ( 9.6 percent) A negative correlation was seen of the early initiation of breast feeding with the age of the mother $(\mathrm{R}=-0.491)$ showing that as the age of the mother increases the rate of early initiation of breast feeding decreases.

The association between the age of the mother and the practice of exclusive breast feeding was found to be significant as it was seen that women who were less than 25 years. of age were more likely to go for the practice of exclusive breast feeding than those who were above 25 years. of age.

Further the association of education status of mother was also seen to be significant with the early initiation and exclusive breast feeding, as it was seen to be a positive correlation and it was also seen that as the educational status of the mother increased there was also an increase in the no. of women going for early initiation of breast feeding.

Further family type, the working status of the respondent were also seen to be important factors affecting the practice of early initiation of breast feeding as well as exclusive breast feeding. Mode of delivery, Place of delivery, ANC, Frequency of ANC was also seen to positively affect the practice of both early initiation and exclusive breast feeding.

Working status was another factor which had a significant 


\begin{tabular}{|l|c|}
\hline Factor & $\begin{array}{c}\text { Level of } \\
\text { significance }\end{array}$ \\
\hline $\begin{array}{l}\text { Association of the age of the mother with early initiation of } \\
\text { breast feeding }\end{array}$ & 0.002 \\
\hline Age of the mother and exclusive breast feeding & 0.003 \\
\hline $\begin{array}{l}\text { education status of mother with early initiation of breast } \\
\text { feeding }\end{array}$ & 0.002 \\
\hline education status of the mother and exclusive breast feeding & 0.001 \\
\hline family type with early initiation of breast feeding & 0.004 \\
\hline family type and exclusive breast feeding & 0.003 \\
\hline the working status of the respondent and exclusive breast & 0.000 \\
\hline feeding & 0.002 \\
\hline working status and early initiation of breast feeding & 0.004 \\
\hline Mode of delivery of the respondent and early initiation of bf & 0.002 \\
\hline mode of delivery and exclusive breast feeding & 0.002 \\
\hline Place of delivery and Early initiation of bf & 0.002 \\
\hline place of delivery and exclusive breast feeding & 0.001 \\
\hline ANC and early initiation of BF & 0.002 \\
\hline ANC and exclusive BF & 0.002 \\
\hline Freq of ANC and early initiation of BF & 0.003 \\
\hline Freq of ANC and exclusive BF & 0.002 \\
\hline Previous knowledge about BF and Exclusive bf & 0.002 \\
\hline Exclusive breast feeding and the sex of the child & 0.003 \\
\hline Colostrum and exclusive breast feeding & 0.002 \\
\hline Early initiation of breast feeding and exclusive breast feeding & \\
\hline
\end{tabular}

Table 4: Factors affecting the breast feeding practices (based on chi-square tests).

association with the practice of exclusive breast feeding as it was seen that mothers who were non-working were more likely to initiate early breast feeding ( 36.45 percent) as compared to those who were working. Along with an influence on the exclusive breast feeding the working status of the mother also had a significant impact on the early initiation of breast feeding as it was seen that 41.1 percent of the non-working mothers had initiated early breast feeding as compared to only 20.1 percent among the working women. On applying logistic regression, the working status was found to be a significant factor with $\mathrm{p}<0.005$.

Also previous knowledge about the importance of breast feeding was a positive factor in relation to the early initiation of breast feeding and exclusive breast feeding as it was seen that those who had prior knowledge were more likely to initiate early breast feeding and exclusive breast feeding as compared to those who did not have prior knowledge regarding the same.

It was also seen that early initiation of breast feeding was in itself an important factor which enhanced the prospects of the women going for exclusive breast feeding. It was seen that 52.7 percent of the mothers who initiated breast feeding within one hour of child birth went on to exclusively breast feed their babies further as compared to 14.1 percent among mothers who did not initiate their breast feeding within one hour. Further it was also seen that for babies who were fed colostrum, 29.1 percent were breast fed exclusively as against 15.3 percent who were not fed colostrum. For both variables, the association was found to bear statistical significance with the breast feeding practices using the chi square and correlation tests.

\section{Discussion}

While studying the practice of exclusive breast-feeding among the participants it was seen that the practice of exclusive breast-feeding was were low among them, i.e., only $24.8 \%$ of the total going for the practice of exclusive breast-feeding while the rest were not following it. There are many factors associated with the practice of breastfeeding including psychosocial factors, maternal socio-demographic characteristics, hospital practices and environmental support. On seeing the association between the age of the mother and the practice of exclusive breastfeeding, it was seen that women who were less than 25 years. Of age were more likely to go for the practice of exclusive breast feeding than those who were above 25 years. of age. There was seen to be a very strong positive association between the educational status of the mother and the exclusive breast feeding practices which mother was following. Further looking at the influence of the family type of the respondent on the early initiation of breast feeding it was seen that family type has a significant influence on both the practices of early initiation of breast feeding as well as exclusive breast feeding along with exclusive breast feeding.

Working status was another factor which had a significant association with the practice of exclusive breast feeding as it was seen that mothers who were non-working were more likely to initiate early breast feeding. Antenatal check-ups also had a significant role and influence on the early initiation of breast feeding as it was seen that those participants who had at least one ANC were more likely to initiate early breast feeding as compared to those who did not go for any ANC [47-49].

\section{Conclusion}

Nutrition has been considered to be one of the basis of a healthy foundation of the future. Breast milk and breast feeding has been considered to be the best nutrition for the new born till the first six months of age. Under nutrition during first two years impairs not only the cognitive development, intelligence, strength, energy and productivity. Child malnutrition occurs entirely during the first two years and is virtually irreversible after that. Optimal feeding practices during first year of life are critical to prevent malnutrition and to ensure optimal health and development of infants. According to the WHO (2003) 60 percent of all deaths under the age of 5 are related to malnutrition. Inappropriate feeding practices are related to $2 / 3 \mathrm{rd}$ of all under five deaths.

According to the most recent estimates published in the Lancet 2003, $13-16 \%$ of all child deaths can be avoided if exclusive breastfeeding was $90 \%$ during first six months and continued breastfeeding was practiced. Another 6\% deaths can be avoided if adequate and appropriate complementary feeding after six months for two years of beyond was provided. Although breast feeding is almost universal in India the rate of early initiation of breast feeding and exclusive breast feeding are dismally low. Several factors can be attributed to this which has a great influence on the breast feeding practices. Inadequate nutrition, breast feeding has been considered to be one major factor responsible for the majority of neo-natal deaths, infant mortality etc. Improving the breast feeding practices can serve as a major determinant in reducing the burden of these deaths and laying the foundations of a healthy future for a new-born [50-52].

Various Government and other agencies have been involved in promoting optimum feeding practices like in 1981, the International Code of Marketing of Breast-milk Substitutes was introduced by the WHO and in 1983, the Indian Govt. adopted a National Code for Protection and Promotion of Breastfeeding. In 1989, further WHO and UNICEF issued a document named 'Protecting, Promoting and Supporting Breast-feeding: The special role of maternity services' which outlined the 'Ten Steps to Successful Breastfeeding'. These became the foundation of Baby Friendly Hospital Initiative (BFHI), which was a global program me launched by the joint collaboration of WHO and UNICEF in 1991. The "Breastfeeding Promotion Network of India (BPNI) "is the national agency for breastfeeding. BPNI is a non- 
Citation: Verma A, Dixit P (2016) Knowledge and Practices of Exclusive Breastfeeding among Women in Rural Uttar Pradesh. J Neonatal Biol 5: 228. doi: $10.4172 / 2167-0897.1000228$

Page 6 of 7

profit, nongovernmental, organization which aims at the protection, promotion, and support of breastfeeding and its activities are funded by UNICEF. Further focus on the various factors which play an important role in the promotion of the practices of early initiation and exclusive breast feeding can further lead to successful implementation of these programs and policies and in turn help in raising and nurturing a healthy child and thus in-turn a healthy youth for the nation.

\section{References}

1. World Bank (2013) Worrying trends in child mortality, Millennium Developmen Goals, the World Bank.

2. WHO/UNICEF (2003) Global strategy for infant and young child feeding. Geneva, World Health Organization.

3. WHO Global Data Bank on Infant and Young Child Feeding (2009).

4. International Institute for Population Sciences (IIPS) and Macro International (2007) National Family Health survey (NFHS-3), 2005-06: India.

5. International Institute for Population Sciences (2008) Ministry of Health and Family Welfare, Government of India. Fact Sheets India, States and Union Territories. District Level Household and Facility Survey 2007-08. Mumbai.

6. Ministry of Health and Family Welfare, Government of India (2009) National Fact Sheet Coverage Evaluation Survey 2009. UNICEF, New Delhi.

7. Infant Survival and Development Report Card Uttar Pradesh (2008) Delhi: Breastfeeding promotion network of India.

8. Patel A, Bucher S, Pusdekar Y, Esamai F, Krebs NF, et al. (2015) Rates and determinants of early initiation of breastfeeding and exclusive breast feeding at 42 days postnatal in six low and middle-income countries: A prospective cohort study. Reprod Health 2: S10.

9. Emmanuel A (2015) A literature review of the factors that influence breastfeeding: An application of the health belief MODEL. International Journal of Nursing and Health Science 2: 28-36.

10. Matsuyama A, Karama M, Tanaka J, Kaneko S (2013) Perceptions of caregivers about health and nutritional problems and feeding practices of infants: A qualitative study on exclusive breast-feeding in Kwale, Kenya. BMC Public Health 13: 1.

11. Kucukoglu S, Celebioglu A (2014) Effect of natural-feeding education on successful exclusive breastfeeding and breastfeeding self-efficacy of low-birthweight infants. Iran J Pediatr 24: 49-56.

12. Veena SR, Krishnaveni GV, Srinivasan K, Wills AK, Hill JC, et al (2009) Infant feeding practice and childhood cognitive performance in South India. Arch Dis Child 95: 347-354

13. Chandhiok N, Singh KhJ, Sahu D, Singh L, Pandey A (2015) Changes in exclusive breastfeeding practices and its determinants in India, 1992-2006: Analysis of national survey data. International Breastfeeding Journal 10: 34.

14. Maonga AR, Mahande MJ, Damian DJ, Msuya SE (2016) Factors affecting exclusive breastfeeding among women in Muheza district Tanga North-eastern Tanzania: A mixed method community based study. Matern Child Health J 20 : $77-87$

15. Bell L, Benoit A, Simoneau-Roy J, Blouin S, Gallagher F (2015) Factors associated with breastfeeding continuation in young Canadian mothers. Sante Publique 27: 7-15.

16. WHO (2003) Global Strategy for infant and young child feeding.

17. WHO (2013) Long-term effects of breastfeeding. A systematic review.

18. WHO (2009) Infant and young child feeding Model Chapter for textbooks for medical students and allied health professionals.

19. Rollins NC, Bhandari N, Hajeebhoy N, Horton S, Lutter CK (2016) Why invest and what it will take to improve breastfeeding And practices. Lancet 387: 491504.

20. Public Health Importance of Optimal Infant and Young Child Feeding Practices (IYCF) (2015) Breastfeeding Promotion Network of India.

21. Chowdhury R, Sinha B, Sankar MJ, Taneja S, Bhandari N, et al. (2015) Breastfeeding and maternal health outcomes: A systematic review and. Acta Pædiatrica 104: 96-113.
22. Rao BS, Mathada VC (2015) Awareness and determinants of contraceptive use among nursing mothers in Bellary, Karnataka. JCDR 10: QC15.

23. Pati S, Chauhan AS, Panda M, Swain S, Hussain MA (2014) Neonatal care practices in a tribal community of Odisha, India: A cultural perspective. Journal of Tropical Pediatrics 60: 238-244.

24. Jain S (2014) Assessment of infant and young child. National Journal of Community Medicine.

25. Tura G, Fantahun M (2015) Neonatal care practice and factors affecting in Southwest Ethiopia: A mixed methods study. BMC International Health and Human Rights 15: 1

26. Victora CG, BahI R, Barros AJ, França GV, Horton S, et al. (2016) Breastfeeding in the 21st century: Epidemiology, mechanisms, and lifelong effect. Lancet 387 $475-490$.

27. Roy MP, Mohan U, Singh SK, Singh VK, Srivastava AK (2014) Determinants of prelacteal feeding in rural northern India. International journal of preventive medicine 1: 5 .

28. Horta BL, Bah R, Martines JC, Victora CG (2007) Evidence on the long-term effects of breastfeeding. Systematic review and meta-analysis. World Health Organization.

29. Bahl R, Frost C, Kirkwood BR, Edmond K, Martines J, et al. (2005) Infant feeding patterns and risks of death and hospitalization in the first half of infancy: multicentre cohort study. Bulletin of the World Health Organization 83: 418-426.

30. Edmond KM, Zandoh C, Quigley MA, Amenga-Etego S, Owusu-Agyei S, Kirkwood BR (2006) Delayed Breastfeeding initiation increases risk of neonatal mortality. Pediatrics 117: 380-386.

31. Breastfeeding Promotion Network of India (BPNI) (2007) About the organisation (Document on the internet) New Delhi.

32. National Guidelines on Infant And Young Child Feeding. New Delhi. Government of India (2004) Ministry of Human Resource Development, Department of Women and Child Development, Food and Nutrition Board Government of India.

33. Hartmann PE, Owns RA, Cox DB (1996) Breast development and control of milk synthesis. Food Nutr Bull 17: 1-10.

34. Gupta A, Gupta YP (2003) Status of infant and young child feeding

35. Kimani-Murage EW, Madise NJ, Fotso JC, Kyobutungi C, Mutua MK, et al. (2011) Patterns and determinants of breastfeeding and complementary feeding practices in urban informal settlements, Nairobi Kenya

36. BMC public Health 11: 1

37. Chudasama RK, Patel PC, Kavishvar AB (2009) Determinants of exclusive breastfeeding in south Gujarat region of India. Journal of Clinical Medicine Research 2: 102-108.

38. Chudasama R, Patel P, Kavishwar, A (2009) Breastfeeding initiation practice and factors affecting breastfeeding in South Gujarat region of India. The Internet Journal of Family Practice 7: 2.

39. Dhandapany G, Bethou A, Arunagirinathan A, Ananthakrishnan S (2008) Antenatal counseling on breastfeeding - Is it adequate? A descriptive study from Pondicherry, India. Int Breastfeed J 4: 3.

40. Agunbiade OM, Ogunleye OV (2012) Constraints to exclusive breastfeeding practice among breastfeeding mothers in Southwest Nigeria: Implications fo scaling up. International Breastfeeding Journal 7: 5.

41. Bandyopadhyay M (2009) Impact of ritual pollution on lactation and breastfeeding practices in rural West Bengal, India. Int Breastfeed J 4:2

42. Awi DD, Alikol EA (2004) Barriers to timely initiation of breastfeeding among mothers of healthy full-term babies who deliver at the University of Teaching Hospital. Niger J ClinPract 9: 57-64.

43. Progress for children (2006) A report card on nutrition. UNICEF.

44. Borade A, Hanumante N (2007) Maternal knowledge and perception about the breast feeding and factors influencing it - A Study in Urban Low Socioeconomic Class of Pune Pediatric Oncall 4: 10.

45. Shirima R, Greiner T, Kylberg E, Gebre-MedhinM (2004) Exclusive breastfeeding is rarely practised in rural and urban Morogoro, Tanzania. Public Health Nutr 2: 147-154. 
Citation: Verma A, Dixit P (2016) Knowledge and Practices of Exclusive Breastfeeding among Women in Rural Uttar Pradesh. J Neonatal Biol 5: 228. doi: $10.4172 / 2167-0897.1000228$

Page 7 of 7

46. Elizabeth KE (2010) Nutrition and Child Development. (4th edn), Paras Medical Publisher, Hyderabad.

47. Kumar D, Agarwal N, Swami HM (2006) Socio-demographic correlates of breast-feeding in urban slums of Chandigarh. Indian J Med Sci 60: 461-466.

48. Pratibha G, Srivastava VK, Kumar V, Jain S, Masood J, et al. (2010) New-born care practices in urban slums of Lucknow city, UP Indian J Community Med 35: 82-85.

49. Motee A, Ramasawmy D, Pugo-Gunsam P, Jeewon R (2013) An assessment of the breastfeeding practices and infant feeding pattern among mothers in Mauritius. Journal of Nutrition and Metabolism 2013: 1-8.
50. Victoria CG, Rajiv Bahl, Barros A, França GVA, Horton S, et al. (2016) Breastfeeding in the 21st century: epidemiology, mechanisms and lifelong effect. The Lancet 10017: 475-490.

51. Bhardwaj N, Hasan SB, Yunus M, Zaheer M (1991) High risk pregnancy and its relation with maternal care receptivity (MCR) - A rural study from India 11 43-46.

52. Gupta AK, Sood RK, Vatsayan A, Dhadwal DK, Ahluwalia SK, Sharma RK(1991) Breast feeding practices in rural and urban communities in a hilly district of North India. 